\title{
Differences in Lower Body Kinematics during Forward Treadmill Skating Between Two Different Hockey Skate Designs
}

\author{
Mike R. Hellyer \\ TESTify Performance, Winnipeg, Canada \\ 91 Lowson Crescent, Winnipeg, R3P 0T3, Canada \\ E-mail: mikerhellyer@gmail.com \\ Marion J.L. Alexander (Corresponding author) \\ Faculty of Kinesiology and Recreation Management, \\ University of Manitoba, Winnipeg, Canada \\ 306 Max Bell Center, Winnipeg, R3T 2N2, Canada \\ E-mail: marion.alexander@umanitoba.ca \\ Cheryl M. Glazebrook \\ Faculty of Kinesiology and Recreation Management, \\ University of Manitoba, Winnipeg, Canada \\ 319 Max Bell Center, Winnipeg, R3T 2N2, Canada \\ E-mail: cheryl.glazebrook@umanitoba.ca \\ Jeff Leiter \\ Pan Am Clinic, Winnipeg, Canada \\ 75 Poseidon Bay, Winnipeg, R3M 3E4, Canada \\ E-mail: jleiter@panamclinic.com
}

Received: 11-10- 2015

doi:10.7575/aiac.ijkss.v.4n.1p.1

URL: http://dx.doi.org/10.7575/aiac.ijkss.v.4n.1p.1

\begin{abstract}
Purpose: The purpose of this study was to investigate the differences in ankle flexibility and skating technique between a traditional hockey skate boot and a hockey skate boot with a flexible rear tendon guard. Skating technique was further investigated at different speeds to give insight on how skating technique alters as skating speed is increased. Methods: Eight elite hockey players were selected for the present study, which was conducted while skating on an Endless Ice Skating Treadmill. Variables were recorded using a three-camera setup and measured from video records at five selected treadmill speeds using the Dartfish Team Pro v6 software. Kinematic variables were then compared between the two skate designs with a doubly multivariate repeated measures design. Statistical significance was set at $\mathrm{p}<0.05$. Results: Post hoc univariate tests comparing skate designs displayed significant increases in plantar flexion, plantar flexion angular velocity, hip extension, hip extension angular velocity, stride length, and stride velocity while participants were wearing the skates that had a flexible rear tendon guard. Significant increases were also displayed in plantar flexion, plantar flexion angular velocity, knee extension, knee extension angular velocity, hip extension, hip extension angular velocity, hip abduction range of motion, hip abduction angular velocity, stride width, stride length, and stride velocity as the treadmill speed increased. There was also a significant decrease in the time the skate was in contact with the treadmill as treadmill speed increased. Conclusion: The results suggested that while skating forward, hockey players could improve their hockey skating technique by using hockey skates that have a flexible rear tendon guard. This flexible tendon guard improved skating technique by increasing the time of force application to the ice by increasing the range of ankle plantar flexion during propulsion of the forward skating stride.
\end{abstract}

Keywords: skate design, plantar flexion, tendon guard

\section{Introduction}

Hockey is a sport that requires a high level of strength, power, and skill. To be successful at the professional level athletes need to be proficient in all the skills required to play the game. Among them, skating is one of the most important (McPherson, Wrigley, \& Montelpare, 2004). Players must be able to skate forwards and backwards, as well as to crossover, pivot, start, and stop during a hockey game. A player that is able to skate fast and change direction 
rapidly has an advantage in puck possession and puck handling. The skilled skater is more often in a position to score a goal or help to stop a goal.

\subsection{Hockey Skate Design}

Past literature has primarily focused on the analysis of the kinematic variables determining skating performance while neglecting the impact of biomechanical changes in skate design (Chang, Turcotte, \& Pearsall, 2009; Lafontaine, 2007; Marino \& Weese, 1979; Upjohn, Turcotte, Pearsall, \& Loh, 2008). There has been minimal research conducted on how the biomechanical design of equipment can affect skating performance (Robert-Lachaine, Turcotte, Dixon, \& Pearsall, 2012). Nevertheless, the performance of a hockey player depends on several factors, including strength, agility, shooting ability, and skating skill, which includes the equipment used during play. A study conducted by Hoshizaki et al. (Hoshizaki, Kirchner, \& Hall, 1989) compared ankle range of motion while skating using different ice hockey skates and concluded that conventional hockey skates restrict the range of motion at the ankle joint for the average hockey player due to the stiff ankle guard. These authors suggested that skate manufacturers should consider altering skate flexibility when designing skates in the future.

The sport of speed skating went through a change in skate design that saw athletes improve skating performance dramatically (Houdijk, Heijnsdijk, de Koning, de Groot, \& Bobbert, 2000). The introduction of the klapskate in $1997-$ 98 allowed speed skaters to keep their blade in contact with the ice longer as they pushed off down the ice. This was done with a hinge placed under the ball of the foot between the skate boot and the blade (Houdijk, Heijnsdijk, et al., 2000). This new hinge allowed the skater to increase the amount of plantar flexion at the end of push off which is correlated to the amount of time the blade is in contact with the ice surface during force production of the forward skating stride. The increase in time the blade is in contact with the ice during force production increases the impulse a forward skater can create against the ice as impulse is the product of force and time (Behm, Wahl, Button, Power, \& Anderson, 2005). This increase in impulse allows the skater to travel faster down the ice.

Although a hinge under the ball of the foot is impractical in the sport of ice hockey due to the variety of skills a hockey player must complete during a game, other design modifications can be made to the traditional hockey skate in order to take advantage of the klapskate design without compromising performance in other skills in which a player must be proficient. Easton hockey has developed a new skate that houses a flexible rear tendon guard (Figure 2). This tendon guard is said to allow added plantar flexion as a hockey skater pushes off the ice surface just as the klapskate does for a speed skater. This added plantar flexion is said to occur without reducing the player's ability to complete other skills that are needed to be an elite ice hockey skater. This skate also has an asymmetrical skate boot with the lateral side constructed five millimeters lower than the medial portion of the boot. This characteristic was designed to promote a larger angle of eversion, which could potentially lead to a longer hockey stride while skating forward (Easton Hockey, 2014).

The results of this study will provide insight into the biomechanical changes a hockey skater can experience while wearing a new skate design that includes a flexible rear tendon guard.

\subsection{Skating and Skate Development}

This study has been designed due to the recent trend in the hockey community to pursue biomechanical advancements in the design of the hockey skate (Hancock, Lamontagne, Stothart, \& Sveistrup, 1999; Pearsall, Paquette, Baig, Albrecht, \& Turcotte, 2012; Pitkin, Smirnova, Scherbina, \& Zvonareva, 2002; Robert-Lachaine et al., 2012; Turcotte, Pearsall, \& Montgomery, 2001). Skate researchers have started to focus on new ways to increase the range of motion at the ankle joint in the traditional hockey skate design. The attempt to develop innovative hockey skate designs, shares the same revolutionary concept of increasing ankle range of motion that the klapskate brought to the sport of speed skating (Hoshizaki, Hall, \& Bourque, 1989; Madore, 2003). This new type of hockey skate design allowing greater ankle plantar flexion should be thoroughly investigated as it has the potential to provide ice hockey players with added joint range of motion, potentially increasing forward skating speed as well as enhancing mobility on skates.

Hockey skate manufacturers have improved skating performance by making skates more stable, reducing their weight, and adding protection for the foot (Robert-Lachaine et al., 2012). The modern hockey skate consists of a skate boot with upper and lower portions, blade holder, and skate blade (Bourque, 1985). Skate boots are now more rigid, possess higher ankle collars and have stiff Achilles tendon guards providing players with stability to help balance over the small skate blade. These characteristics also protect the skater's ankle from the opponent's sharp skate blades and sticks along with hard rubber pucks travelling at excessive speeds.

Although these characteristics provide the athlete with stability and protection they also limit the skater from producing a full range of motion at the ankle (Robert-Lachaine et al., 2012). This reduction in ankle range of motion could possibly lead to limiting the range of motion not only at the ankle but also at the knee and hip, ultimately reducing a player's maximum skating speed.

\subsection{The Klapskate}

The ice skates used in speed skating went through a revolutionary transformation in 1997-98. This time period saw the introduction of the klapskate which enabled athletes to instantly improve skating performance as they shattered all of the current world speed skating records (Houdijk, Wijker, De-Koning, Bobbert, \& De-Groot, 2001). The speed at which speed skaters could skate increased by $0.3 \mathrm{~m} / \mathrm{s}$ in the first year alone (Kuper \& Sterken, 2003). It was presented by 
Houdijk et al. (Houdijk, De Koning, De Groot, Bobbert, \& Van Ingen Schenau, 2000) that klapskates not only enabled skaters to skate at a higher velocity, $10 \mathrm{~m} / \mathrm{s}$ compared to $9.6 \mathrm{~m} / \mathrm{s}$, but also maintained an equal velocity at a lower metabolic level compared to the conventional skate. The difference between the conventional speed skate and the klapskate was that the klapskate was equipped with a hinge between the boot and blade under the ball of the foot. This hinge allowed the skater to plantarflex the foot at the end of push-off while the entire blade of the skate remained in contact with the ice (Houdijk, De Koning, et al., 2000).

It has been established that the range of motion occurring at the ankle joint influences the range of motion at the knee joint during sport performance (Haguenauer, Legreneur, \& Monteil, 2006). When comparing push-offs in speed skating between conventional speed skates and klapskates, experts (Houdijk, Heijnsdijk, et al., 2000) concluded that klapskates, which enabled the skater to increase the range of motion at the ankle, also increased the work output at the knee joint. In the final $50 \mathrm{~ms}$ of force production during the skating stride the center of pressure of the propulsion force reaches the ball of the skaters foot. The center of pressure will stay under the ball of the foot for speed skaters wearing the klapskate, as the hinge placed under the ball of the foot allows the entire skate blade to stay in contact with the ice as the skater plantarflexes the ankle. A skater wearing a conventional skate design will see the center of pressure pass from the ball of the foot and move forward to the end of the blade. This occurs because the entire skate blade is fixed to the boot of the conventional skate design (Houdijk, De Koning, et al., 2000).

The skate blade must also be rotated laterally and positioned perpendicular to the direction of force applied by the skater. This is necessary to grip the ice with the inside edge of the blade producing enough friction to develop a propulsive force. If this perpendicular position of the skate blade is not met the skate will slip forwards or backwards due to the lack of frictional force applied to the ice by the skate blade. The klapskate design allows the skater to direct the propulsive force perpendicular to the blade of the skate as the ankle is plantar flexed and the knee is fully extended.

This transpires as the klapskate keeps the blade in a perpendicular position until the knee reaches full extension. As a skater reaches the maximum amount of plantar flexion while wearing the restrictive conventional skate, fully extending the knee will now create a forward directed force relative to the skate blade. Therefore, it is a position of knee flexion during the latter stages of propulsion that is required to direct the propulsive force perpendicular to the skate blade while wearing the conventional skate. This prevents the knee from fully extending and contributing in the later stages of force production during forward skating (Houdijk, De Koning, et al., 2000).

\subsection{Ankle Range of Motion}

Haguenauer et al. (Haguenauer et al., 2006) also compared the effects ankle range of motion has on the knee joint. Elite figure skaters performed vertical jumps on a force plate for three separate conditions: barefoot, wearing a $1.5 \mathrm{~kg}$ ankle mass on both legs simulating the weight of the skates, and while wearing figure skates. These authors found that the stiff design of the figure skate boot decreased the athlete's ability to jump by limiting plantar flexion at the ankle joint. This decrease in ankle joint range of motion had significant implications on the knee joint during leg extension. Haguenauer et al. (Haguenauer et al., 2006) concluded that participants displayed significant decreases in knee extension at the instant of toe-off when wearing the restrictive skate boot. This finding is in agreement with that of Houdijk et al. (Houdijk, De Koning, et al., 2000) that reducing the amount of ankle plantar flexion an athlete has will reduce the amount of knee extension during extension of the lower limbs which is crucial in force production during forward skating in ice hockey.

The purpose of this study was to investigate the differences in ankle flexibility and skating technique between a traditional hockey skate boot and a hockey skate boot with a flexible rear tendon guard. Skating technique was further investigated at different speeds to give insight on how skating technique alters as skating speed is increased.

\section{Methods}

\subsection{Participants}

The participants for this study consisted of highly skilled male hockey players with Canadian Interuniversity Sport or professional hockey experience. A power analysis based on data from the pilot study was conducted to determine the sample size required for this study. A significance level (alpha) of 0.05 and type two-error beta of 0.2 was set to produce a desired power of at least 0.80 . Using $G *$ Power version 3 software it was determined that a minimum of eight participants were required to ensure adequate power (Faul, Erdfelder, Lang, \& Buchner, 2007). There was no compensation offered to participants for taking part in this study. The Easton Mako skates (Easton Hockey, 2014) were obtained for the duration of the study from an Easton sales representative located in Winnipeg, Manitoba.

Prior to the study, participants were required to provide written consent by signing an informed consent form approved by the ENREB research group from the University of Manitoba. Participants then signed a Physical Activity Readiness Questionnaire for Everyone from the Canadian Society for Exercise Physiology (CSEP) (Quinn, 2015) and answered a short questionnaire to collect information including: height $(\mathrm{cm})$, mass $(\mathrm{kg})$, age, hockey experience, and brand of the current skate. 
Table 1. Descriptive characteristics of participants

\begin{tabular}{lllll}
\hline & \multicolumn{2}{c}{ Mean \pm SD } & \multicolumn{2}{c}{ Range } \\
\hline Age & 25.50 & \pm 3.42 & 20.0 & -30.0 \\
Height $(\mathrm{m})$ & 1.80 & \pm 0.08 & $1.68-1.90$ \\
Mass (kg) & 82.55 & \pm 11.29 & $68.04-102.06$ \\
Hockey Experience (Years) & 18.5 & \pm 2.14 & $16.00-22.00$ \\
\hline
\end{tabular}

All skates were sharpened with a 0.5 inch hollow and similar rocker radius by Custom Edge Skate Service to help eliminate differences between the two pairs of skates.

\subsection{Skates Used}

Each participant's personal skates were considered the traditional skate design for this study. The materials the participant's personal skates were made from may have differed slightly from other skates on the current market but the biomechanical properties of a high ankle collar, and stiff Achilles tendon guard are consistent with other modern skates on store shelves.
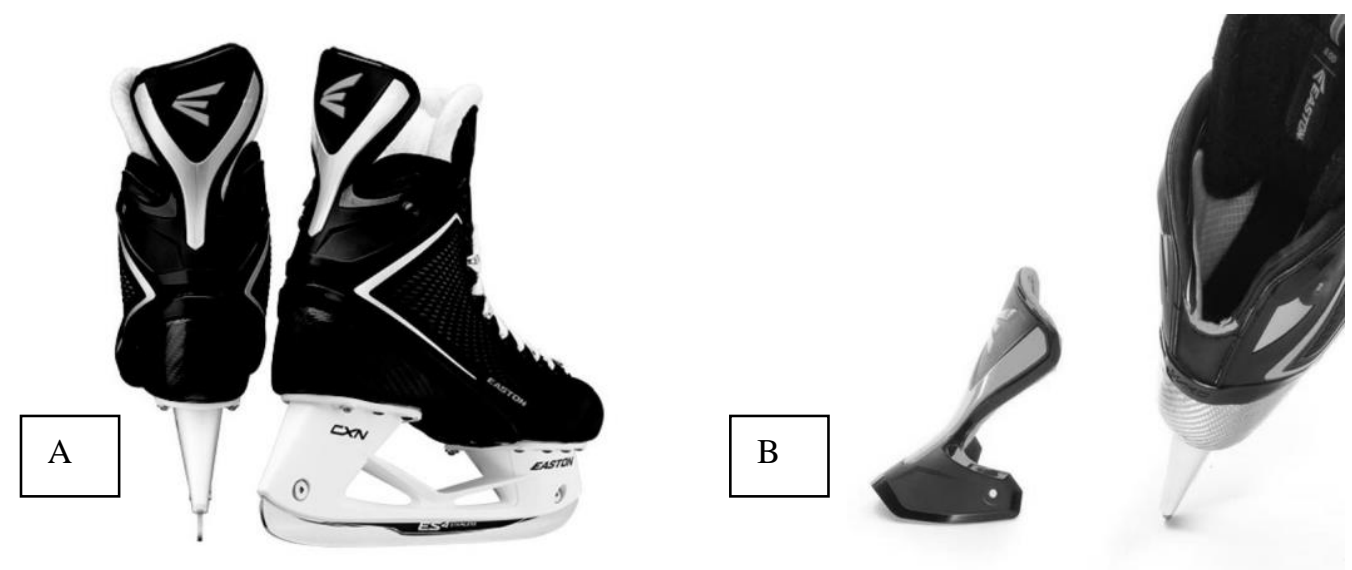

Figure 1. Easton Mako skate (retrieved from: http://hockeysupremacy.com ) (A); Flexible rear tendon guard on Easton Mako (retreived from: http://purehockey.com ) (B)

The Easton Mako hockey skate (Figure 1) served as the experimental skate design during this study. This skate was chosen due to the unique biomechanical characteristics it possesses. This new skate design includes a raised heel, an asymmetrical skate boot with the medial side sitting five millimeters taller than the lateral side of the boot and an active extendon guard on the rear of the skate boot (Figure 1)(Easton Hockey, 2014).

\subsection{Ankle Flexibility Measurements}

Ankle flexibility measurements were taken with a Canon GL2 video camera. Ankle movements were clearly seen in the video footage, which were then determined using Dartfish Team Pro v6 (Dartfish, 2014). This included both passive and active range of motion testing for the ankle in three different conditions: wearing no skate, wearing the current skate they were using (traditional design), and wearing the Easton Mako skate (Easton Hockey, 2014). Ankle dorsiflexion and plantar flexion were measured with participants lying supine on a table (Clarkson, 2000) (Figure 3). To simulate the position of the lower limb during hockey skating, a rolled towel was placed under the knee to maintain $20^{\circ}$ to $30^{\circ}$ of knee flexion. 


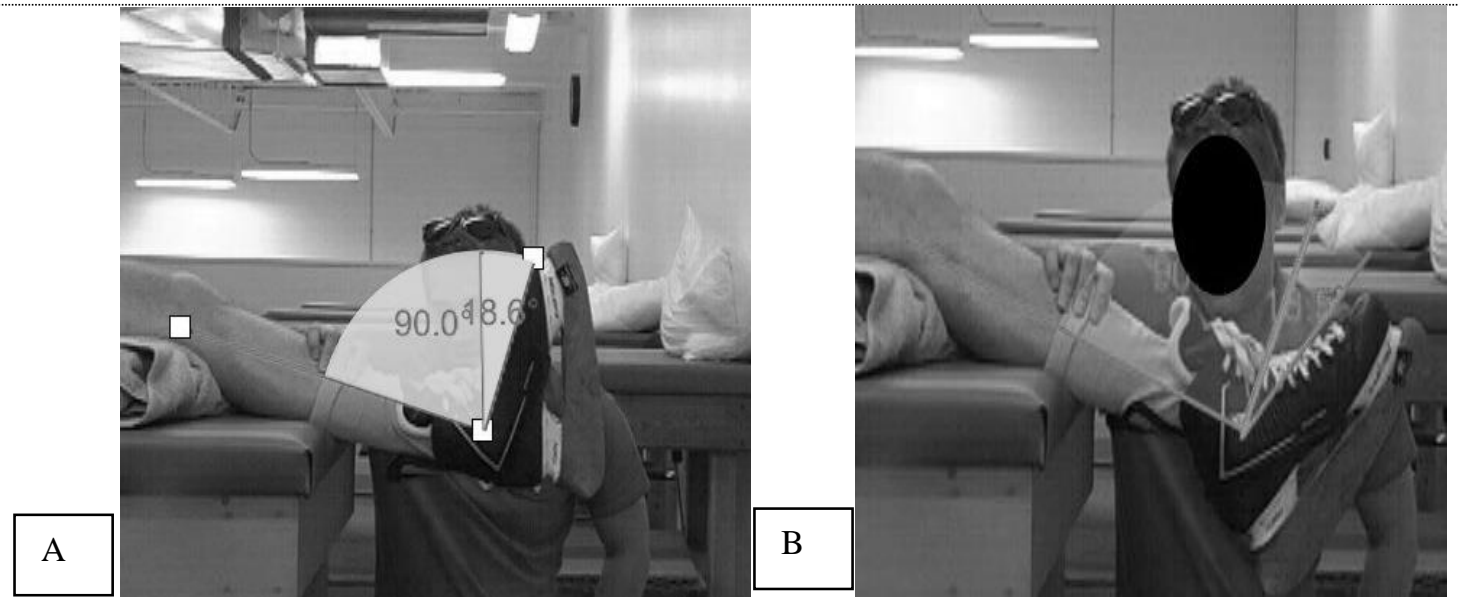

Figure 2. Measurement of ankle dorsiflexion $\left(18.6^{\circ}\right)$ and plantarflexion $\left(18.5^{\circ}\right)$ while wearing the Easton Mako skate.

The tibia and fibula were stabilized with the axis of rotation marked just inferior to the lateral malleolus. The stationary arm of the joint was placed parallel to the longitudinal axis of the fibula with the movable arm of the joint marked parallel to the inferior aspect of the heel eliminating forefoot movement from the measurement. Ankle dorsiflexion and plantar flexion were measured while wearing the hockey skate with the same procedure. This was accomplished by measuring the distance between points on the lower limb and the lateral malleolus to help estimate it's position within the hockey skate boot (Figure 2).

Inversion and eversion of the subtalar joint were measured with the participant lying prone and the feet positioned beyond the end of the table (Clarkson, 2000) (Figure 3). The ankle was set in a neutral position with two markings on the skin being placed over the midline of the superior aspect of the calcaneus. The stationary arm of the joint was placed parallel to the longitudinal axis of the lower leg with the movable arm of the joint being placed along the midline of the posterior aspect of the calcaneus in line with the mark on the heel pad posteriorly (Clarkson, 2000). Inversion and eversion with the hockey skate was measured with the same procedure however the movable arm was modified to align with the center of the skate blade, as the mark on the heel pad was not visible.

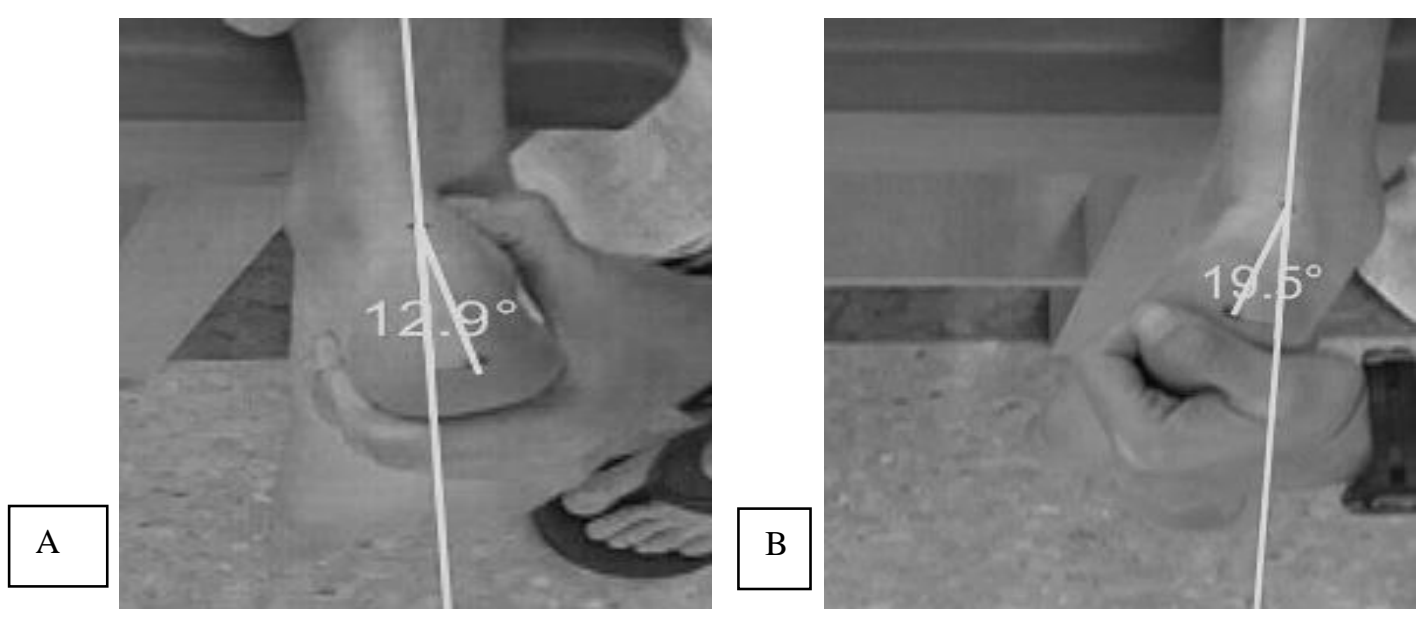

Figure 3. Measurement of subtalar inversion $\left(19.5^{\circ}\right)$ and eversion $\left(12.9^{\circ}\right)$ with no skate.

\subsection{Skating Data Collection}

Filming of the participants while skating took place on an Endless Ice skating treadmill (Figure 4). A three-camera setup was used to capture video for the right side of the body. A Canon GL2 camera was used to film the sagittal view from the right. This camera was placed on a tripod approximately $2.30 \mathrm{~m}$ from the skating zone. A Fujifilm EXR camera was attached to a tripod and fixed to the wall in front of the skating treadmill at an approximate distance of 2.4 $\mathrm{m}$ from the skating zone capturing data in the frontal plane. A third camera (Canon GL2) was placed in the direction of the stride of the right leg. The position of this camera varied according to the participant to remain in line with his/her right leg. 


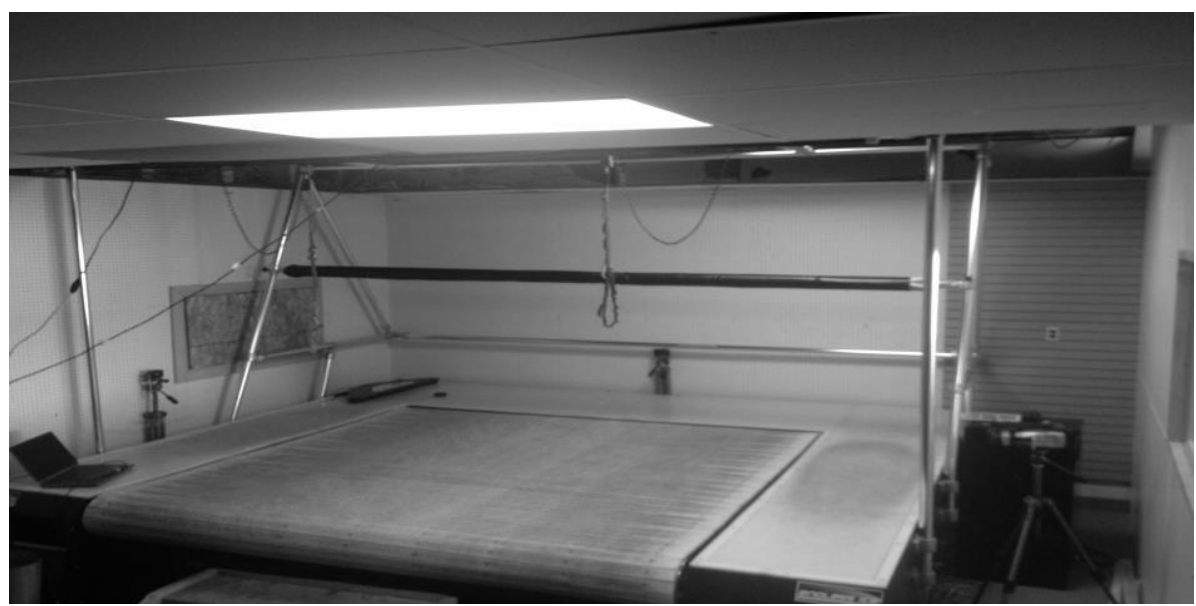

Figure 4. Endless ice skating treadmill.

Participants were instructed by the researcher to perform a dynamic warm-up consisting of approximately five minutes of aerobic activity and five minutes of total body calisthenics. Following the warm up participants were randomly selected to the traditional group $(\mathrm{nr}=4$; wearing the traditional skates) or the Easton Mako group ( $\mathrm{nr}=4$; wearing the Easton Mako skates). Each participant was then outfitted with body markers at the right hip (RHIP) and right knee (RKNE). RHIP was located at the superior aspect of the right greater trochanter while RKNE was located at the lateral femoral epicondyle of the right knee. These marker locations are consistent with the protocol normally used in the University of Ottawa's gait laboratory and proved to be robust for consistently estimating joint angles (Robertson, 2012).

Participants were then attached to a safety harness that was connected to an overhead tracking system by a weighted kill switch. This weighted switch was wired to the control panel and served as an emergency shut off. In addition to the weighted switch a padded bar was positioned across the front of the treadmill for participants to grasp helping prevent injury in the case of a fall. A fifteen-minute familiarization period was then given to the participants so they could become accustomed to skating on the treadmill. This familiarization period was instructed by a WinnPro Hockey (Winnpro Hockey, 2015) instructor and included forward skating, both bilateral and unilateral edge control drills, and one legged squats. Participants then skated at three different velocities $3.33 \mathrm{~m} / \mathrm{s}(8 \mathrm{mph}), 5.00 \mathrm{~m} / \mathrm{s}(11 \mathrm{mph})$, and $6.66 \mathrm{~m} / \mathrm{s}(14 \mathrm{mph})$ for $20 \mathrm{~s}$ each with a two-minute rest between trials. These speeds were based on self-selected treadmill skating speeds of elite hockey players, while the time-interval gives sufficient time for the video cameras to gather at least 20 consecutive strides at each speed (Chang et al., 2009).

Participants then skated at two additional speeds. This portion of the test consisted of skating at speeds of $6.71 \mathrm{~m} / \mathrm{s}(15$ $\mathrm{mph})$ and $8.05 \mathrm{~m} / \mathrm{s}(18 \mathrm{mph})$ for $20 \mathrm{~s}$ with a $30 \mathrm{~s}$ rest period between intervals. Participants then changed into the second pair of skates depending on their initial skate selection group. Another familiarization period was completed, then participants performed the same task while wearing the second pair of skates.

\subsection{Skating data processing}

The measurement of joint angles was conducted using the angle tool in analyzer mode of Dartfish v6 (Dartfish, 2014 ). All variables were expressed with respect to reference anatomical position, i.e. upright posture, arms down at the sides, and the palms face forward (Baechle, Earle, \& National Strength, 2008). There were two positions of interest when calculating variables related to the position of the push off leg while skating: weight acceptance and propulsion. Weight acceptance was considered the position when the heel of the skate blade came in contact with the treadmill just after recovery of the right leg. Propulsion was considered the position when the toe of the right skate blade was last seen in contact with the treadmill prior to takeoff.

Ankle dorsiflexion, knee flexion, hip flexion, hip adduction, hip abduction, and hip adduction were measured at weight acceptance. Ankle plantar-flexion, knee flexion, hip flexion, and hip abduction were measured at propulsion. Each variable was measured for each subject during ten consecutive strides at each of the five speeds while wearing both skate designs. For the purposes of this study a stride was defined as the time from weight acceptance to propulsion. To ensure the most accurate angle possible the display video full screen mode was used. Ankle plantar-flexion range of motion was obtained from the positions of ankle dorsiflexion at weight acceptance and ankle plantar-flexion at propulsion.

Knee extension range of motion was calculated by subtracting the amount of knee flexion the participant had at propulsion from the amount of knee flexion obtained at weight acceptance (Figure 5). Hip extension range of motion was measured by subtracting the amount of hip flexion at propulsion from the amount of hip extension at weight acceptance (Figure 6). In the case where a participant did not show a recovery past a neutral position, hip abduction range of motion was calculated by subtracting the amount of hip abduction at weight acceptance from the amount of hip abduction at propulsion (Figure 7). If the participant showed hip adduction at weight acceptance, it was added to the amount of hip abduction at propulsion to calculate the range of hip abduction. 

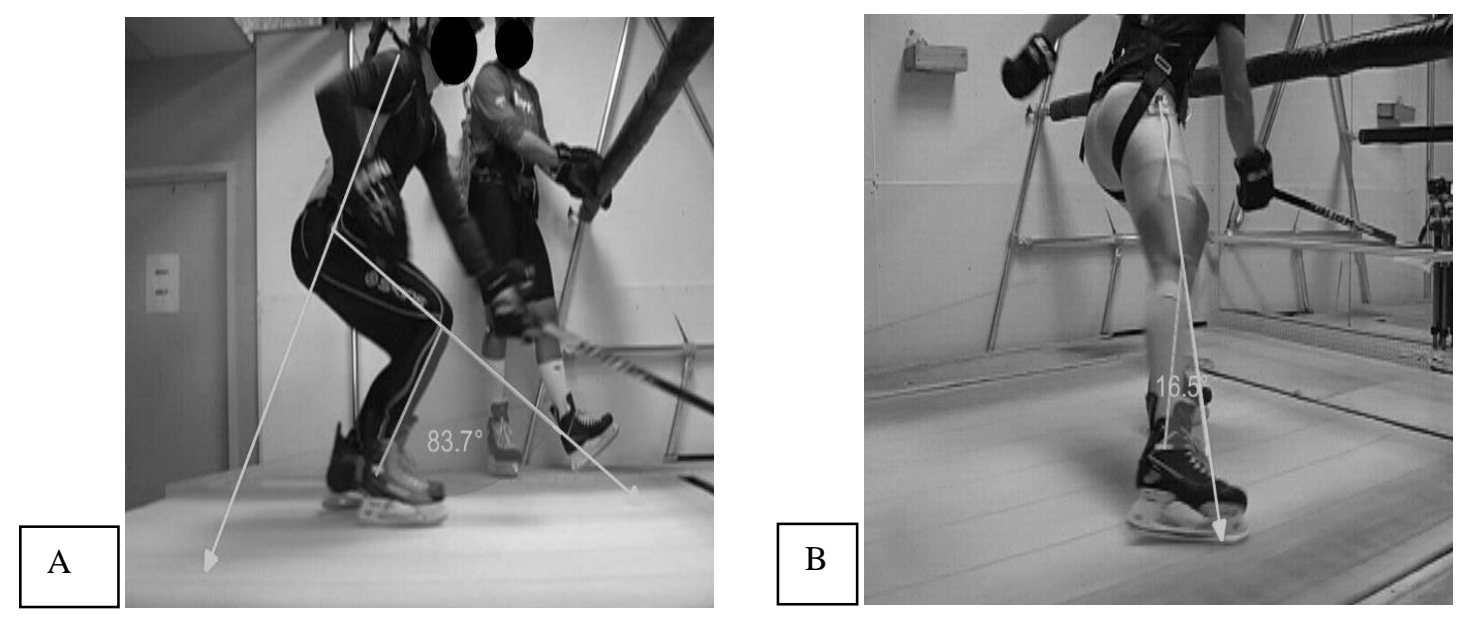

Figure 5. Knee flexion at weight acceptance (A); Knee flexion at propulsion (B)
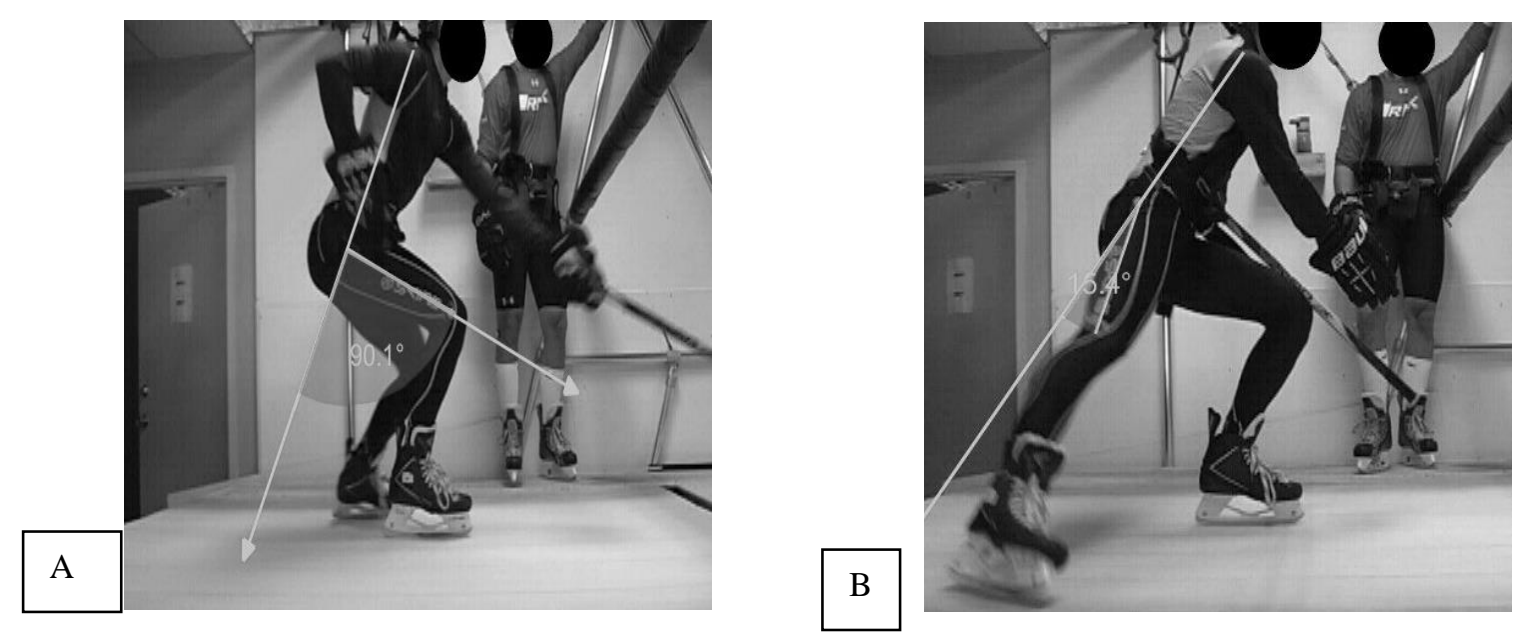

Figure 6. Hip flexion at weight acceptance (A); Hip flexion at propulsion (B)
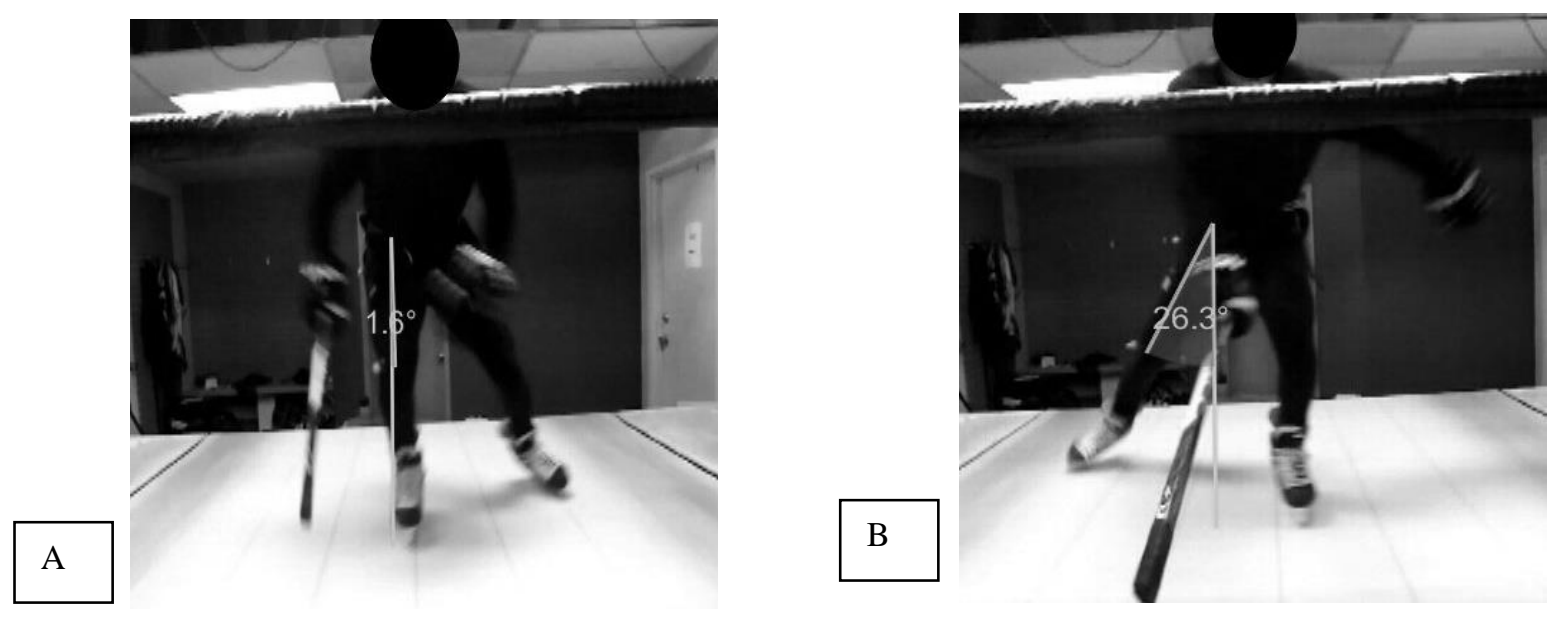

Figure 7. Hip adduction at weight acceptance (A); Hip abduction at propulsion (B)

Stride length was calculated by using the distance tool in the analyzer mode of Dartfish (Dartfish, 2014). Stride length in the sagittal plane was then measured as the distance the skate blade travelled from weight acceptance to propulsion. The distance the skate blade traveled in the frontal plane from weight acceptance to propulsion was then calculated to be stride width (Figure 8). Total stride length was then calculated by using Pythagorean theorem. 



Figure 8. Stride length in the sagittal plane (A); Stride width in the frontal plane (B)

Blade time on the treadmill was calculated as the time from weight acceptance to propulsion by using the time tool in analyzer mode (Dartfish, 2014). Ankle plantar-flexion angular velocity, knee extension angular velocity, hip extension angular velocity, hip abduction angular velocity, and stride velocity were then calculated by dividing their prospective range of motions by blade time on ice. All variables were measured for ten consecutive strides of the right leg while wearing both the traditional skate and Easton Mako skate at $3.33 \mathrm{~m} / \mathrm{s}(8 \mathrm{mph}), 5.00 \mathrm{~m} / \mathrm{s}(11 \mathrm{mph}), 6.66 \mathrm{~m} / \mathrm{s}(14 \mathrm{mph})$, $6.71 \mathrm{~m} / \mathrm{s}(15 \mathrm{mph})$, and $8.05 \mathrm{~m} / \mathrm{s}(18 \mathrm{mph})$.

\subsection{Statistical Analyses}

Statistical analyses were undertaken to compare the skating technique between two skate types and were performed using the SPSS 20 statistical software ("IBM SPSS software," 2013). Means and standard deviations of all the variables estimated during the testing were calculated when participants were wearing no skate, the traditional skate, and the Easton Mako skate. Differences in passive and active ranges of motion along with the type of skate were examined using a doubly multivariate repeated-measures test. Post hoc univariate tests and planned pairwise comparisons were then completed to determine where the differences in range of motion occurred between the three conditions of no skate, traditional skate, and Easton Mako skate. A Bonferroni correction was used as it is recommended when the univariate tests produce values that are not exactly equal to alpha, but are less than alpha in most situations (Lix \& Sajobi, 2010).

Means and standard deviations of all the variables measured while participants were skating on a treadmill were calculated for 10 consecutive strides per condition. A total of 10 conditions were analyzed in the present study, the traditional skate at five speeds and the Easton Mako skate at five speeds. Differences between skate design and treadmill speed were then calculated with a doubly multivariate repeated-measures design. In the present study there were two independent variables (skate type/treadmill speed) and 13 dependent variables. There were two levels of skate type (Traditional/Easton Mako), and 5 levels of treadmill speed $(3.33 \mathrm{~m} / \mathrm{s}, 5.00 \mathrm{~m} / \mathrm{s}, 6.66 \mathrm{~m} / \mathrm{s}, 6.71 \mathrm{~m} / \mathrm{s}, 8.05 \mathrm{~m} / \mathrm{s})$. Post hoc univariate tests and planned pairwise comparisons were also completed to determine where the differences in skating kinematics occurred. A Bonferroni adjustment was once again used to help control for a Type 1 error (Lix \& Sajobi, 2010). Statistical significance was set at $\mathrm{p}<0.05$ for all tests. A correlation analysis was also completed to determine which variables were associated with increased skating speed.

\section{Results}

\subsection{Participants}

\subsection{Ankle Flexibility Measurements}

The doubly multivariate repeated-measures test displayed significant differences between passive and active range of motion yielding a significance value of $\mathrm{p}=.025$ (Table 2).

Table 2. Multivariate results for pre-procedure range of motion

\begin{tabular}{lcccc}
\hline Within Subjects Effect & F & Hypothesis df & Error df & Significance \\
\hline Passive ROM vs Active ROM & 9.526 & 4.000 & 4.000 & .025 \\
Skate Type & 7.104 & 8.000 & 22.000 & .000 \\
\hline
\end{tabular}


Post hoc univariate tests (Table 3$)$ displayed significant differences between eversion $(\mathrm{p}=.001)$ and inversion $(\mathrm{p}=.003)$ along with non-significant differences in dorsiflexion $(\mathrm{p}=.919)$ and plantar flexion $(\mathrm{p}=.655)$. Further complex contrast comparisons revealed that passive eversion range of motion displayed a mean increase of $3.1^{\circ}(p=.001)$ when compared to active eversion range of motion. Passive inversion range of motion displayed a mean increase of $6.3^{\circ} \mathrm{p}=.003$ ) greater than active inversion range of motion.

Table 3. Univariate tests comparing passive and active range of motion $(* \mathrm{p}<.05)$.

\begin{tabular}{llcccc}
\hline Measure & Range of Motion & Mean & Std.Error & F & Significance \\
\hline Dorsiflexion & Passive & 20.2 & 0.78 & \multirow{2}{*}{0.011} & .919 \\
& Active & 20.1 & 0.90 & & \\
Plantar flexion & Passive & 21.2 & .0 .88 & 0.218 & .655 \\
& Active & 20.9 & 0.73 & & \\
\multirow{5}{*}{ Inversion } & Passive & 11.4 & 0.79 & 27.419 & $.001^{*}$ \\
& Active & 8.3 & 0.75 & & \\
& Passive & 20.2 & 1.77 & \multirow{2}{*}{20.311} & $.003^{*}$ \\
& Active & 13.9 & 0.93 & & \\
\hline
\end{tabular}

Table 4. Unvariate tests comparing no skate, traditional skate, and Easton Mako skate $(* \mathrm{p}<.05)$.

\begin{tabular}{llcccc}
\hline Measure & Skate Type & Mean & Std.Error & F & Significance \\
\hline Dorsiflexion & No skate & 21.1 & 1.84 & & \\
& Traditional & 20.7 & 1.06 & .950 & .410 \\
& Easton Mako & 18.8 & 0.62 & & \\
Plantar flexion & No skate & 31.3 & 2.23 & & $.000^{*}$ \\
& Traditional & 13.0 & 1.49 & 28.555 & \\
& Easton Mako & 18.9 & 0.66 & & .376 \\
Eversion & No skate & 10.8 & 1.16 & & \\
& Traditional & 8.7 & 0.67 & 1.006 & $.007^{*}$ \\
& Easton Mako & 10.0 & 1.40 & & \\
\hline
\end{tabular}

The doubly multivariate repeated-measures test also produced a significant difference $(\mathrm{p}=.000)$ when comparing the three conditions: wearing no skate, wearing their own skate, and wearing the Easton Mako skate (Table 2). Post hoc univariate tests (Table 4) indicated differences in plantar flexion range of motion $(\mathrm{p}=.000)$ and inversion range of motion $(\mathrm{p}=.007)$ with non-significant differences in dorsiflexion $(\mathrm{p}=.410)$ and eversion $(\mathrm{p}=.376)$. Complex contrast comparisons further determined that plantar flexion while wearing no skate was shown to have an increase of $18.4^{\circ}$ $(\mathrm{p}=.001)$ when compared to the participant's own skate. As well, plantar flexion was greater by $12.5^{\circ}(\mathrm{p}=.003)$ when compared to the Easton Mako skate. There was a mean increase in plantar flexion of $5.9^{\circ}(\mathrm{p}=.003)$ when participants were wearing the Easton Mako skate compared to their own skate. Participants wearing no skate displayed a mean increase of $6.0^{\circ}(\mathrm{p}=.012)$ of inversion range of motion when compared to wearing the Easton Mako skate.

\subsection{Skating Experimental Acquisitions}

The means and standard errors of the 13 variables were calculated for all eight participants while wearing their own traditional hockey skate and the Easton Mako skate. The results of the doubly multivariate repeated measures test suggested significant differences in skating technique within both skate design $(\mathrm{p}=.022)$ and treadmill speed $(\mathrm{p}=.000)$ (Table 5).

Table 5. Multivariate results for the skating treadmill test

\begin{tabular}{lcccc}
\hline Within Subjects Effect & F & Hypothesis df & Error df & Significance \\
\hline Skate & 1248.638 & 7.000 & 1.000 & .022 \\
Speed & 3.512 & 52.000 & 64.079 & .000 \\
\hline
\end{tabular}

Post hoc univariate tests were then completed on each variable to determine differences in skating kinematics while participants skated using the two different skate designs. Significant differences were observed between ankle plantar flexion range of motion $(\mathrm{p}=.000)$, ankle plantar flexion angular velocity $(\mathrm{p}=.003)$, hip extension range of motion 
$(p=.039)$, hip extension angular velocity $(p=.020)$, stride length $(p=.041)$, and stride velocity $(p=.011)$. In all cases the variables related to range of motion and angular velocity increased when using the Easton Mako skate. There were no significant differences shown in knee extension range of motion $(\mathrm{p}=.133)$, knee extension angular velocity $(\mathrm{p}=.098)$, hip abduction range of motion $(\mathrm{p}=.299)$, hip abduction angular velocity $(\mathrm{p}=.553)$, sagittal stride length $(\mathrm{p}=.065)$, stride width $(\mathrm{p}=.520)$, and skate time on the treadmill $(\mathrm{p}=.087)$ when comparing skate designs.

The planned contrast comparisons, Table 6 and Table 7 display the differences between skate design in both range of motion and angular/linear velocity respectively. Ankle plantar flexion range of motion was $6.2^{\circ}$ larger while participants were wearing the Easton Mako skate. Ankle plantar flexion angular velocity was also significantly larger while participants were wearing the Easton Mako skate showing an increase of $9.8 \%$. Participants also displayed significant increases in hip extension range of motion $\left(1.7^{\circ}\right)$ and hip extension angular velocity $\left(5.4^{\circ} / \mathrm{s}\right)$ while wearing the Easton Mako skate. Significant increases in stride length $(0.1 \mathrm{~m})$ and stride velocity $(0.2 \mathrm{~m} / \mathrm{s})$ were also evident with participants sporting the Easton Mako skate.

Table 6. Mean range of motion measured comparisons between skate designs while skating on a treadmill $(*=\mathrm{p}<.05)$.

\begin{tabular}{|c|c|c|c|c|}
\hline Measure & Skate & Mean & $\begin{array}{c}\text { Absolute Mean } \\
\text { Difference }\end{array}$ & Standard Error \\
\hline \multirow{2}{*}{ Plantar flexion (degrees) } & Traditional & 13.5 & \multirow{2}{*}{$6.2 *$} & 1.94 \\
\hline & Mako & 19.7 & & 1.97 \\
\hline \multirow{2}{*}{ Knee extension (degrees) } & Traditional & 45.4 & \multirow{2}{*}{2.8} & 2.56 \\
\hline & Mako & 48.2 & & 3.61 \\
\hline \multirow{2}{*}{ Hip extension (degrees) } & Traditional & 50.3 & \multirow{2}{*}{$1.7 *$} & 1.81 \\
\hline & Mako & 52.0 & & 1.81 \\
\hline \multirow{2}{*}{ Hip abduction (degrees) } & Traditional & 34.1 & \multirow{2}{*}{0.8} & 3.16 \\
\hline & Mako & 33.3 & & 2.84 \\
\hline \multirow{2}{*}{ Sagittal stride length (meter) } & Traditional & 0.9 & \multirow{2}{*}{0.1} & 0.04 \\
\hline & Mako & 1.0 & & 0.03 \\
\hline \multirow{2}{*}{ Stride width (meter) } & Traditional & 0.7 & \multirow{2}{*}{0.0} & 0.03 \\
\hline & Mako & 0.7 & & 0.04 \\
\hline \multirow{2}{*}{ Stride length (meter) } & Traditional & 1.2 & \multirow{2}{*}{$0.1^{*}$} & 0.03 \\
\hline & Mako & 1.3 & & 0.02 \\
\hline
\end{tabular}

\subsection{Treadmill Speed and Skating Technique}

Significant differences were displayed in ankle plantar flexion range of motion $(\mathrm{p}=.000)$, ankle plantar flexion angular velocity $(\mathrm{p}=.000)$, knee extension range of motion $(\mathrm{p}=.000)$, knee extension angular velocity $(\mathrm{p}=.000)$, hip extension range of motion $(\mathrm{p}=.000)$, hip extension angular velocity $(\mathrm{p}=.000)$, hip abduction range of motion $(\mathrm{p}=.000)$, hip abduction angular velocity $(\mathrm{p}=.000)$, stride width $(\mathrm{p}=.000)$, stride length $(\mathrm{p}=.006)$, stride velocity $(\mathrm{p}=.000)$, and skate time on the treadmill $(\mathrm{p}=.000)$ as treadmill speed increased from $3.33 \mathrm{~m} / \mathrm{s}$ to $8.05 \mathrm{~m} / \mathrm{s}$. No significant difference was found between speed and sagittal stride length $(\mathrm{p}=.101)$.

Table 7. Mean angular and linear velocity measured comparisons between skate designs while skating on a treadmill $(*=\mathrm{p}<.05)$.

\begin{tabular}{|c|c|c|c|c|}
\hline Measure & Skate & Mean & $\begin{array}{c}\text { Absolute Mean } \\
\text { Difference }\end{array}$ & Standard Error \\
\hline \multirow{2}{*}{$\begin{array}{l}\text { Plantar flexion angular velocity } \\
\text { (degrees/s) }\end{array}$} & Traditional & 19.4 & \multirow{2}{*}{$9.8^{*}$} & 2.47 \\
\hline & Mako & 29.3 & & 3.00 \\
\hline \multirow{2}{*}{$\begin{array}{l}\text { Knee extension angular velocity } \\
\text { (degrees/s) }\end{array}$} & Traditional & 66.0 & \multirow{2}{*}{5.9} & 3.52 \\
\hline & Mako & 71.9 & & 5.16 \\
\hline \multirow{2}{*}{$\begin{array}{l}\text { Hip extension angular velocity } \\
\text { (degrees/s) }\end{array}$} & Traditional & 73.2 & \multirow{2}{*}{$5.4^{*}$} & 4.42 \\
\hline & Mako & 78.6 & & 5.04 \\
\hline \multirow{2}{*}{$\begin{array}{l}\text { Hip abduction angular velocity } \\
\text { (degrees/s) }\end{array}$} & Traditional & 48.3 & \multirow{2}{*}{0.8} & 2.18 \\
\hline & Mako & 49.1 & & 1.53 \\
\hline \multirow{2}{*}{ Stride velocity (meter/s) } & Traditional & 1.7 & \multirow{2}{*}{$0.1^{*}$} & 0.08 \\
\hline & Mako & 1.8 & & 0.09 \\
\hline \multirow{2}{*}{ Skate time on treadmill (seconds) } & Traditional & .70 & \multirow{2}{*}{0.0} & 0.03 \\
\hline & Mako & .70 & & 0.04 \\
\hline
\end{tabular}


Table 8 and 9 display planned pairwise comparisons between $3.33 \mathrm{~m} / \mathrm{s}$ and $8.05 \mathrm{~m} / \mathrm{s}$. Participants exhibited an increase in ankle plantar flexion range of motion of $5.1^{\circ}(\mathrm{p}=.000)$ as speed went from $3.33 \mathrm{~m} / \mathrm{s}$ to $8.05 \mathrm{~m} / \mathrm{s}$. A significant increase in ankle plantar flexion angular velocity of $13.1 \% \mathrm{~s}(\mathrm{p}=.000)$ was also shown as speed increased. Knee extension range of motion $\left(12.2^{\circ}, \mathrm{p}=.000\right)$ and angular velocity $\left(34.6^{\circ} / \mathrm{sec}, \mathrm{p}=.036\right)$ also increased with skating speed.

Significant increases in hip extension range of motion $\left(8.3^{\circ}, \mathrm{p}=.001\right)$ and hip extension angular velocity $(30.9 \%$, $\mathrm{p}=.000$ ) were also observed as speed increased from $3.33 \mathrm{~m} / \mathrm{s}$ to $8.05 \mathrm{~m} / \mathrm{s}$. Increases of $6.4^{\circ}$ in hip abduction range of motion ( $\mathrm{p}=.001)$ and $20.8 \% \mathrm{sec}$ of hip abduction angular velocity $(\mathrm{p}=.000)$ were also observed as speed increased. As participants skating speed increased sagittal stride length $(0.1 \mathrm{~m}, \mathrm{p}=.016)$, stride width $(0.1 \mathrm{~m}, \mathrm{p}=.001)$, stride length $(0.2 \mathrm{~m}, \mathrm{p}=.001)$, and stride velocity $(0.6 \mathrm{~m} / \mathrm{s}, \mathrm{p}=.000)$ all increased significantly. Finally as skating speed increased from $3.33 \mathrm{~m} / \mathrm{s}$ to $8.05 \mathrm{~m} / \mathrm{s}$ there was a significant decrease in the amount of time participants skates were in contact with the treadmill of 0.2 seconds $(\mathrm{p}=.000)$.

Table 8. Mean range of motion measured comparisons between $3.33 \mathrm{~m} / \mathrm{s}$ and $8.05 \mathrm{~m} / \mathrm{s}(*=\mathrm{p}<.05)$.

\begin{tabular}{llccc}
\hline Measure & Speed $(\mathrm{m} / \mathrm{s})$ & Mean & $\begin{array}{c}\text { Absolute Mean } \\
\text { Difference }\end{array}$ & Standard Error \\
\hline Plantar flexion (degrees) & 3.33 & 13.4 & $5.1^{*}$ & 1.78 \\
& 8.05 & 18.5 & & 1.81 \\
Knee extension (degrees) & 3.33 & 39.6 & $12.2^{*}$ & 3.37 \\
& 8.05 & 51.8 & & 3.26 \\
Hip extension (degrees) & 3.33 & 47.2 & $8.3^{*}$ & 2.05 \\
& 8.05 & 55.5 & & 1.91 \\
Hip abduction (degrees) & 3.33 & 30.1 & $6.4^{*}$ & 2.86 \\
& 8.05 & 36.5 & & 3.17 \\
Sagittal stride length (meter) & 3.33 & 0.9 & 0.1 & 0.03 \\
& 8.05 & 1.0 & & 0.04 \\
Stride width (meter) & 3.33 & 0.6 & $0.1^{*}$ & 0.03 \\
Stride length (meter) & 8.05 & 0.7 & & 0.04 \\
& 3.33 & 1.1 & $0.2^{*}$ & 0.03 \\
\hline
\end{tabular}

Table 9. Mean angular and linear velocity measured comparisons between treadmill speeds $3.33 \mathrm{~m} / \mathrm{s}$ and $8.05 \mathrm{~m} / \mathrm{s}(*=\mathrm{p}<.05)$.

\begin{tabular}{llccc}
\hline Measure & Speed $(\mathrm{m} / \mathrm{s})$ & Mean & $\begin{array}{c}\text { Absolute Mean } \\
\text { Difference }\end{array}$ & Standard Error \\
\hline Plantar flexion angular & 3.33 & 16.7 & $13.1^{*}$ & 1.83 \\
velocity (degrees/s) & 8.05 & 29.8 & & 2.76 \\
Knee extension angular & 3.33 & 49.6 & $34.6^{*}$ & 2.93 \\
velocity (degrees/s) & 8.05 & 84.2 & & 5.88 \\
Hip extension angular & 3.33 & 60.1 & $30.9^{*}$ & 2.92 \\
velocity (degrees/s) & 8.05 & 91.0 & & 5.79 \\
Hip abduction angular & 3.33 & 37.2 & $20.8^{*}$ & 1.69 \\
velocity (degrees/s) & 8.05 & 58.0 & & 2.10 \\
Stride velocity (meter/s) & 3.33 & 1.4 & $0.6^{*}$ & 0.07 \\
Skate time on treadmill & 8.05 & 2.0 & & 0.09 \\
(seconds) & 3.33 & 0.8 & $0.2^{*}$ & 0.04 \\
\hline
\end{tabular}

\subsection{Variables associated with Skating Speed}

The correlations between the treadmill speed and the variables measured during the skating treadmill test are reported in Table 10. Through examination of the correlation analysis it was evident that the angular velocity occurring at each joint displayed a higher correlation with treadmill speed than did the range of motion occurring about the joint. Hip abduction angular velocity had the highest correlation with treadmill speed. This variable had a high positive correlation (0.778) with treadmill speed, indicating that as the treadmill speed was increased the skaters increased their 
angular velocity of hip abduction. Knee extension angular velocity also had a high positive correlation (0.658) with increasing treadmill speed, which suggests that increases in the skater's angular velocity at the knee was associated with the increase in treadmill speed. Stride velocity was the variable to produce the next highest positive correlation (0.605) followed by hip extension angular velocity (0.587) and plantar flexion angular velocity (0.442). Positive correlations between treadmill speed and the range of motion occurring about each joint displayed moderate $r$ values for hip extension (0.435) and knee extension (0.427), with small $r$ - values being observed in ankle plantar flexion (0.267) and hip abduction (0.263).

Sagittal stride length had a small $\mathrm{r}$ value of 0.250 , suggesting a weak positive association. Moderate $\mathrm{r}$ values were calculated for both stride width (0.377) and stride length $(0.381)$, indicating that stride width and stride length increased as the treadmill speed increased. An r-value of -0.466 representing skate blade contact time suggested that there was a moderate negative correlation between the time the skate blade was on the treadmill and treadmill speed. This means that as treadmill speed increased the time the skate blade was on the treadmill decreased.

Table 10. Correlation between treadmill speed and variables measured. $\left(* \mathrm{p}<.05,{ }^{*} \mathrm{p}<.01\right)$

Correlation $\mathrm{n}=80$

\begin{tabular}{lcc} 
Variable & r-value & Significance \\
\hline Ankle Plantar Flexion & 0.267 & $0.017^{*}$ \\
Ankle Plantar Flexion Angular Velocity & 0.442 & $0.000^{* *}$ \\
Knee Extension & 0.427 & $0.000^{* *}$ \\
Knee Extension Angular Velocity & 0.658 & $0.000^{* *}$ \\
Hip Extension & 0.435 & $0.000^{* *}$ \\
Hip Extension Angular Velocity & 0.587 & $0.000^{* *}$ \\
Hip Abduction & 0.263 & $0.018^{*}$ \\
Hip Abduction Angular Velocity & 0.778 & $0.000^{* *}$ \\
Sagittal Stride Length & 0.250 & $0.025^{*}$ \\
Stride Width & 0.377 & $0.001^{* *}$ \\
Stride Length & 0.381 & $0.000^{* *}$ \\
Stride Velocity & 0.605 & $0.000^{* *}$ \\
Skate Blade Time on Ice & -0.466 & $0.000^{* *}$ \\
\hline
\end{tabular}

\section{Discussion}

\subsection{Ankle Flexibility Measurements}

The purpose of the present study was to investigate the effect skate design has on ankle flexibility and lower body kinematics during the propulsive phase of forward hockey skating. Changing the biomechanical design of the hockey skate, which is a piece of equipment that plays a huge role in determining whether an athlete is successful, may lead to significantly improving a player's ability to excel over their opponents. The present study analyzed differences in passive and active dorsiflexion, plantar flexion, eversion, and inversion while participants were wearing no skate, their own skate, and the Easton Mako skate.

Significant differences were found between both plantar flexion $(\mathrm{p}=.000)$ and inversion $(\mathrm{p}=.007)$. Plantar flexion was greatest when players were wearing no skate $\left(31.3^{\circ}\right)$ followed by the Easton Mako skate $\left(18.9^{\circ}\right)$ and finally the traditional skate design $\left(13.0^{\circ}\right)$. Although the Easton Mako skate increased ankle plantar flexion range of motion when compared to the traditional skate design it was evident that the player was still restricted from using their entire range of motion. New skate designs that allow participants to use more of this available range of motion at the ankle joint should be investigated in future studies. This may have a positive effect on increasing forward skating performance. The Easton Mako skate did not show any significant difference in eversion range of motion when compared to the traditional skate design ( $\mathrm{p}=0.376)$. The design of the new skate boot with the medial side sitting five millimeters higher than the lateral side was designed to promote eversion and increase a player's ability to turn on the ice. Future studies should investigate differences in eversion while skating to understand the implications an asymmetrical skate boot such as the Easton Mako has on performance.

\subsection{Skating Experimental Acquisitions}

Lower body kinematic comparisons while skating on a treadmill were the primary focus of this study. Thirteen variables were measured during the propulsive phase of the hockey stride, for eight participants, while skating forwards on a skating treadmill. Through the statistical analysis there were significant differences found in lower body 
kinematics between the two skate designs $(\mathrm{p}=.022)$. These findings are consistent with two authors (Robert-Lachaine et al., 2012; Tidman, 2014) who also reported that a change in the biomechanical design of the hockey skate can alter skating kinematics. There was also an observed significant difference in lower body kinematics as the speed of the treadmill increased $(\mathrm{p}=.000)$. These findings are consistent with several authors (Haguenauer et al., 2006; Houdijk, De Koning, et al., 2000; Page, 1975; Upjohn et al., 2008) that found lower body kinematics change as skating speed is increased.

The results of this study supported the primary research hypothesis, i.e. that lower limb kinematics are influenced by skate design. In fact both plantar flexion range of motion and plantar flexion angular velocity significantly differed as athletes utilized the two different skate designs. Plantar flexion range of motion was found to be $6.2^{\circ}$ larger while participants were wearing the Easton Mako skate $\left(19.7^{\circ}\right)$ when compared to the traditional skate design $\left(13.5^{\circ}\right)$. These findings are similar to those of Robert-Lachaine et al. (Robert-Lachaine et al., 2012) who found plantar flexion values of $16^{\circ}$ in participants using a skate with a flexible rear tendon guard and Upjohn et al. (Upjohn et al., 2008) who found plantar flexion values of $13.5^{\circ}$ for participants using a traditional skate design. This increased range of motion will increase the propulsive output aiding players to skate faster down the ice. Plantar flexion angular velocity was also significantly increased by $9.8 \%$ with the use of the Easton Mako skate $(29.2 \%$ ) when compared to the traditional design $(19.4 \% \mathrm{~s})$. This difference together with the increased range of motion exhibited by the use of this new skate design indicates that not only was the range of motion larger while wearing the Easton Mako, but also the movement was occurring at a faster rate. Assuming the recovery phase of the stride does not change while using this new skate design, the increase in angular velocity will increase the stride rate, which is a characteristic of faster skaters (Page, 1975; Upjohn et al., 2008).

While investigating a hockey skate with a flexible back tendon Robert-Lachaine et al. (Robert-Lachaine et al., 2012) discovered that the "total peak force occurred later during plantar flexion which suggested the increased range of motion resulted in a more prolonged effective force generation during a given skating stride" (pg. 205). The increased range of motion displayed in the current study by the implementation of the Easton Mako skate therefore suggests that players will generate greater force from the plantar flexors during the hockey stride when compared to the traditional skate design. This increase in force generation, along with the increase in angular displacement of the ankle, increases the total work produced by the skater. Due to this increase in total work (W) and the increase in angular velocity $(\omega)$ seen while participants were wearing the Easton Mako skate we know that the power output $(P=T \times \omega)$, which is a characteristic of faster skaters, was higher when participants were using the Easton Mako skate compared to the traditional design. Increasing both work and power during a given time period enables a skater to travel faster down the ice (Vaughan, 1988).

Luhtanen and Komi (Luhtanen \& Komi, 1978) found the plantar flexors of the ankle to be important contributors in vertical jumping. They found the plantar flexors to contribute $22 \%$ of the total vertical jump height. This suggests that, as the ankles are concentrically plantar flexed during the forward hockey stride the plantar flexors play an important role in producing force into the ice. Given the evidence provided by these studies hockey players should be using skates that enable them to use the plantar flexors to their maximal capability.

As the treadmill speed increased from $3.33 \mathrm{~m} / \mathrm{s}$ to $8.05 \mathrm{~m} / \mathrm{s}$ there were again significant differences in both plantar flexion range of motion $\left(5.1^{\circ}\right)$ and plantar flexion angular velocity $\left(13.1^{\circ} / \mathrm{s}\right)$. While skating at $3.33 \mathrm{~m} / \mathrm{s}$ plantar flexion range of motion was shown to be $13.4^{\circ}$ and increased to $18.5^{\circ}$ at a speed of $8.05 \mathrm{~m} / \mathrm{s}$. Participants exhibited $16.7^{\circ} / \mathrm{s}$ of plantar flexion angular velocity while skating at $3.33 \mathrm{~m} / \mathrm{s}$ and $29.83 \% \mathrm{~s}$ of plantar flexion angular velocity at $8.05 \mathrm{~m} / \mathrm{s}$. This again agrees with authors Robert-Lachaine et al. and Vaughn (Robert-Lachaine et al., 2012; Vaughan, 1988) that increased plantar flexion range of motion and increased plantar flexion angular velocity lead to faster skating. Taking into account that plantar flexion range of motion and angular velocity increased as speed increased we can conclude the Easton Mako improves performance at the ankle joint allowing participants to skate faster as it led to an increase in both plantar flexion range of motion and plantar flexion angular velocity.

\subsection{Skate Design implications on Knee Extension}

In the present study there was no significant difference in knee extension range of motion or knee extension angular velocity as skate design was altered. Recent literature has concluded that the range of motion occurring at the ankle joint during athletic movements affects the kinematics of the knee joint. When comparing push-offs in speed skating between conventional speed skates and klapskates, Houdijk et al. (Houdijk, De Koning, et al., 2000) concluded that klapskates, which increased the range of motion at the ankle, increased the work output at the knee joint. Another study investigating the effects ankle range of motion has on the vertical jump during figure skating Haguenauer (Haguenauer et al., 2006) concluded that the stiff design of the figure skating boot decreased performance by limiting plantar flexion, decreasing work at the ankle joint, and decreasing knee angular velocity. According to Upjohn et al. (Haguenauer et al., 2006), this was done by restricting movement at the ankle joint causing a "redistribution of the energy produced by the knee extensors to the hip and ankle joints" (p. 706). The findings of the current study do not agree with these previous studies, as there was no increase in knee extension range of motion or knee extension angular velocity as plantar flexion range of motion and angular velocity increased.

Although not significant the present study calculated a mean increase of $2.8^{\circ}$ in knee extension range of motion while participants were wearing the Easton Mako skate $\left(48.2^{\circ}\right)$ when compared to the traditional skate design $\left(45.4^{\circ}\right)$. These 
values are similar to those reported by Lafontaine (Lafontaine, 2007) that knee extension values of 55.6 and Upjohn et al. (Upjohn et al., 2008) who reported knee extension values of $34.8^{\circ}$. The slight increase in knee extension during the present study when compared to those of Upjohn et al. (Upjohn et al., 2008) may be attributed to the use of faster treadmill speeds. An increase of $5.9^{\circ}$ in knee extension angular velocity was also a non-significant observation when comparing the Easton Mako skate $(71.9 \%$ s) to the traditional skate design $(66.0 \%)$. Contrary to previous studies by Haguenauer et al. and Houdijk et al. (Haguenauer et al., 2006; Houdijk, De Koning, et al., 2000) the present study does not substantiate that producing significant increases in joint range of motion at the ankle leads to significantly increasing the knee extension range of motion during propulsion in forward ice skating. However the Easton Mako skate did not limit range of motion or angular velocity at the knee joint which is important to hockey players as faster skaters exhibit increases in both of these characteristics when compared to slower skaters (Upjohn et al., 2008). As the treadmill speed increased from $3.33 \mathrm{~m} / \mathrm{s}$ to $8.05 \mathrm{~m} / \mathrm{s}$ knee extension range of motion significantly increased from $39.6^{\circ}$ to $51.8^{\circ}$, while knee extension angular velocity significantly increased from $49.6 \%$ so $84.2 \%$. The results of the current study agree with authors Upjohn et al. (Upjohn et al., 2008) and Page (Page, 1975) that faster skaters exhibit greater knee extension and knee angular velocity. It is therefore important to further investigate the effects that increasing ankle range of motion may have on the knee during forward skating in hockey as it could lead to an increase in skating speed.

Hip extension range of motion and hip extension angular velocity were significantly different as participants changed skate designs. The Easton Mako skate outperformed the traditional skate design once again when it came to hip extension kinematics. Hip extension range of motion was increased by $1.7^{\circ}$ while participants were wearing the Easton Mako skate $\left(52.0^{\circ}\right)$ when compared to the traditional skate design $\left(50.3^{\circ}\right)$. These values are similar to those of Upjohn et al. (Upjohn et al., 2008) who reported hip extension range of motion to be $40.3^{\circ}$. The slight increase in hip extension between the two studies could once again be attributed to the different treadmill speeds. This increase in hip extension allows skaters to increase the force production by the hip extensors during the propulsion phase. This increase in range of motion also places the hip flexor muscles in a position of greater tension as they reach toe off. The greater tension induces the hip flexors to be pre-stretched which stores energy in both of its elastic and contractile components. This ultimately induces a stronger force as the hip flexors contract at the beginning of recovery (Nordin \& Frankel, 2012). This stronger contraction will make for a faster recovery during the swing phase of the hockey stride increasing stride rate, which is a characteristic of faster skaters (Page, 1975; Upjohn et al., 2008).

The Easton Mako skate (78.6\%) also improved angular velocity of the hip extensors during propulsion when compared to the traditional skate design $(73.2 \%$ ). This increase in angular velocity, which is a characteristic of elite skaters, increases the power they have in the lower legs to propel them down the ice at faster speeds. Hip extension and hip extension angular velocity were also significantly affected by the speed in which participants were skating. Hip extension range of motion increased $8.3^{\circ}$ from $47.2^{\circ}$ to $55.5^{\circ}$. These values are slightly larger than the $40.3^{\circ}$ of hip extension range of motion reported by Upjohn et al. (Upjohn et al., 2008) due to the variance in treadmill speeds. Hip extension angular velocity was increased by $30.9 \%$ from $60.1 \%$ s to $91.0 \%$ s as the treadmill speed increased from 3.33 $\mathrm{m} / \mathrm{s}$ to $8.05 \mathrm{~m} / \mathrm{s}$. These increases are in agreement with de Koning et al. (de Koning, de Groot, \& van-Ingen-Schenau, 1989) who concluded as skating speed is increased, hip extension range of motion and hip extension angular velocity also increase. Due to this increased activity at the hip joint players wearing this skate design rather than a traditional skate design will potentially skate faster.

\subsection{Correlation Analysis}

The correlation analysis completed from the skating treadmill test variables produced significant associations between all 13 variables and treadmill speed (Table 10). The highest $r$-values were present in the angular velocities occurring at each joint. These results indicated that as skating speed increased the angular velocities in the hip, knee and ankle also increased. The higher correlations observed in angular velocities when compared to the correlations present in the range of motion of the lower limbs suggest that increases in angular velocity may be more important than increases in joint range of motion when it comes to increasing skating speed. This high correlation of angular velocity agrees with several authors (Bracko, 2009; de Koning, Thomas, Berger, De Groot, \& van Ingen Schenau, 1995; Upjohn et al., 2008) who found increases in angular velocities of the joints of the lower limbs to be a characteristic of faster skaters.

The stride characteristics presented similar results. Although a moderate correlation existed between treadmill speed and both stride width (0.377) and stride length (0.381), the r-value was higher for stride velocity (0.605). These results suggest that stride velocity or the rate in which it takes a player to go from weight bearing to propulsion, may be the most important stride characteristic a player should focus on when trying to increase skating speed.

\section{Conclusion and Practical Applications}

The purpose of this study was to investigate the differences in ankle flexibility and skating technique between a traditional hockey skate boot and a hockey skate boot with a flexible rear tendon guard. Skating technique was further investigated at different speeds to give insight on how skating technique alters as skating speed is increased.

It was hypothesized that the skate design with a flexible rear tendon guard would increase both range of motion and angular velocity occurring at the ankle, knee, and hip during propulsion of the forward skating stride. It was also hypothesized that this new skate design would increase stride length, stride width, and stride velocity during propulsion.

Based on the findings of this study the following conclusions appear justified: 
- Ankle plantar flexion range of motion and ankle plantar flexion angular velocity during propulsion of the forward skating stride are increased when using a skate with flexible rear tendon guard.

- Hip extension range of motion and hip extension angular velocity during propulsion of the forward skating stride are increased when using a skate with flexible rear tendon guard.

- Hockey players increased stride length and stride velocity of propulsion when using a skate that has a flexible rear tendon guard.

- The time the skate was in contact with the treadmill during propulsion was decreased with the implementation of a flexible rear tendon guard.

Improvements in hockey skate design have important implications for the skating skill of elite hockey players. Success in ice hockey is closely related to skating skill and is partially dependent on push off forces and joint ranges of motion allowed by a particular skate design. A skate design that allows for increased range of motion at the ankle joint during push off has the potential to increase skating speed and agility by increasing the contribution from the ankle plantarflexors such as gastrocnemius and soleus as well as the knee extensors. A slight tilt of the skate sole in the direction of eversion may also improve the angle of the skate blade with regard to utilizing the inside edge for a longer period during push off. More study is required examining other unique skate designs that increase the range of motion at key skating joints to determine which designs have the greatest potential for improving hockey skating speed and agility.

\section{References}

Baechle, T. R., Earle, R. W., \& National Strength, C. A. (2008). Essentials of Strength Training and Conditioning. Champaign, IL: Human Kinetics.

Behm, D. G., Wahl, M. J., Button, D. C., Power, K. E., \& Anderson, K. G. (2005). Relationship between hockey skating speed and selected performance measures. The Journal of Strength \& Conditioning Research, 19(2), 326-331.

Bourque, R. (1985). Canada Patent No.: US Patent No. 4, 276.

Bracko, M. R. (2009). Enhancing Performance in ice hockey. In M. Duncan \& M. Lyons (Eds.), Advances in Strength and Conditioning Research (pp. 243-254). Hauppauge, NY: Nova Publishers.

Chang, R., Turcotte, R., \& Pearsall, D. (2009). Hip adductor muscle function in forward skating. Sports Biomechanics, $8(3), 212-222$.

Clarkson, H. M. (2000). Musculoskeletal assessment: joint range of motion and manual muscle strength. Philadelphia: Lippincott Williams \& Wilkins.

Dartfish, I. (2014). Dartfish Digital Video Analysis System. Retrieved from http://www.dartfish.com/en/sportsenhancements/sport_performance_software/index.htm

de Koning, J. J., de Groot, G., \& van-Ingen-Schenau, G. J. (1989). Mechanical aspects of the sprint start in Olympic speed skating. Int J Sport Biom, 5(2), 151-168.

de Koning, J. J., Thomas, R., Berger, M., De Groot, G., \& van Ingen Schenau, G. J. (1995). The start in speed skating: from running to gliding. Medicine and Science in Sports and Exercise, 27(12), 1703-1708.

Easton Hockey. (2014). Easton Hockey. Retrieved from http://eastonhockey.com/gear/products/skates/mako-skate

Faul, F., Erdfelder, E., Lang, A. G., \& Buchner, A. (2007). G* Power 3: A flexible statistical power analysis program for the social, behavioral, and biomedical sciences. Behavior Research Methods, 39(2), 175-191.

Haguenauer, M., Legreneur, P., \& Monteil, K. M. (2006). Influence of figure skating skates on vertical jumping performance. Journal of Biomechanics, 39(4), 699-707.

Hancock, S., Lamontagne, M., Stothart, J. P., \& Sveistrup, H. (1999). The influence of three hockey skate boots on the range of motion, elastic moment and stiffness of the human ankle joint complex. Paper presented at the Proceedings from XVIth Conference of the International Society of Biomechanics, Calgary, Canada.

Hoshizaki, T. B., Hall, K., \& Bourque, R. (1989). Montreal, Canada Patent No.: US. Patent No. 4, 885.

Hoshizaki, T. B., Kirchner, G., \& Hall, K. (1989). Safety in Ice Hockey: Kinematic analysis of the talocrural and subtalar joints during the hockey skating stride. American Society for Testing and Materials, 1, 141 .

Houdijk, H., De Koning, J. J., De Groot, G., Bobbert, M. F., \& Van Ingen Schenau, G. J. (2000). Push-off mechanics in speed skating with conventional skates and klapskates. Medicine and Science in Sports and Exercise, 32(3), 635-641.

Houdijk, H., Heijnsdijk, E. A., de Koning, J. J., de Groot, G., \& Bobbert, M. F. (2000). Physiological responses that account for the increased power output in speed skating using klapskates. European Journal of Applied Physiology and Occupational Physiology, 83(4-5), 283-288.

Houdijk, H., Wijker, A. J., De-Koning, J. J., Bobbert, M. F., \& De-Groot, G. (2001). Ice friction in speed skating: can klapskates reduce ice frictional loss? Medicine-and-science-in-sports-and-exercise-, 33(3), 499-504.

Kuper, G. H., \& Sterken, E. (2003). Endurance in speed skating: The development of world records. European Journal of Operational Research, 148(2), 293-301. 
Lafontaine, D. (2007). Three-dimensional kinematics of the knee and ankle joints for three consecutive push-offs during ice hockey skating starts. Sports Biomechanics, 6(3), 391-406

Lix, L. M., \& Sajobi, T. (2010). Testing multiple outcomes in repeated measures designs. Psychological Methods, 15(3), 268.

Luhtanen, P., \& Komi, P. V. (1978). Segmental contribution to forces in vertical jump. European Journal of Applied Physiology and Occupational Physiology, 38(3), 181-188.

Madore, C. (2003). Montreal, Canada Patent No.: U. Patent.

Maor, E. (2007). The Pythagorean Theorem: A 4,000-year History. Princeton: Princeton University Press.

Marino, G. W., \& Weese, R. G. (1979). A kinematic analysis of the ice skating stride. In J. Terauds (Ed.), Science in Skiing, Skating and Hockey. Del Mar, CA: Academic Publishers.

McPherson, M. N., Wrigley, A., \& Montelpare, W. J. (2004). The biomechanical characteristics of development-age hockey players: Determining the effects of body size on the assessment of skating technique. American Society for Testing and Materials (ASTM), Special Technical Publication (pp. 272-287).

Nordin, M., \& Frankel, V. H. (2012). Basic biomechanics of the musculoskeletal system (4th ed.). Philadelphia, PA: Lippincott Williams \& WIlkins.

Page, P. (1975). Biomechanics of forward skating in ice hockey. (MSc), Dalhousie University, Halifax.

Pearsall, D. J., Paquette, Y. M., Baig, Z., Albrecht, J., \& Turcotte, R. A. (2012). Ice hockey skate boot mechanics: Direct torque and contact pressure measures. Procedia Engineering, 34, 295-300.

Pitkin, M., Smirnova, L., Scherbina, K., \& Zvonareva, E. (2002). Biomechanics of ice hockey skating in amputees with foot and ankle prostheses. Paper presented at the Proceedings of the 7th Annual Russian National Congress, St. Petersburg, Russia.

Quinn, E. (2015). PAR-Q- The physical activity readiness questionnaire. About Health. Retrieved from http://sportsmedicine.about.com/od/fitnessevalandassessment/qt/PAR-Q.htm

Robert-Lachaine, X., Turcotte, R. A., Dixon, P. C., \& Pearsall, D. J. (2012). Impact of hockey skate design on ankle motion and force production. Sports Engineering, 15(4), 197-206.

Robertson, D. G. E. (2012). Vicon Workstation Quick Reference Guide (PDF). Retrieved from http://www.health.uottawa.ca/biomech/courses/apa4311/Vicon\%20Workstation\%20Quick\%20Reference\%20Guide.pdf Robertson, D. G. E. (2004). Research Methods in Biomechanics. Champaign, IL: Human Kinetics.

Tidman, R., Lambert, L., Cruikshank, D., \& Silver-Thorn, M. . (2014). Hockey Skating Kinematics. Paper presented at the Proceedings of the Marquette University Biomedical Engineering Symposium, Milwaukee, WI.

Turcotte, R. A., Pearsall, D. J., \& Montgomery, D. L. (2001). An apparatus to measure stiffness properties of ice hockey skate boots. Sports Engineering, 4(1), 43-48.

Upjohn, T., Turcotte, R., Pearsall, D. J., \& Loh, J. (2008). Three-dimensional kinematics of the lower limbs during forward ice hockey skating. Sports Biomechanics, 7(2), 206-221.

Vaughan, C. L. (1988). Biomechanics of Speed Skating Biomechanics of Sport (1st edition). Boca Raton: CRC Press.

Winnpro Hockey. (2015). Winnpro Hockey. Retrieved from http://www.winnprohockey.com/About.html 